\title{
Extraction, phytochemical analysis and in silico antidepressant studies of aqueous extract of leaves of Hibiscus sabdariffa $\mathrm{L}$.
}

\author{
Mohd Mohiuddin Shareef and E. Bhavya \\ School of Pharmaceutical Sciences, Vels Institute of Science, Technology and Advanced Studies, Pallavaram, Chennai-600117, Tamil Nadu,
} India

\section{Article Info}

Article history

Received 1 October 2021

Revised 15 November 2021

Accepted 16 November 2021

Published Online 30 December 2021

\begin{tabular}{l}
\hline Keywords \\
Delphinidin \\
FTIR \\
HPLC \\
GC-MS \\
2 z5y protein
\end{tabular}

$2 \mathrm{z} 5 \mathrm{y}$ protein

\begin{abstract}
The aim of study is to extract Hibiscus sabdariffa L. leaves, evaluate their phytochemical properties, and screen in silico antidepressant effects. It is commonly called as roselle belongs to family Mallows or Malvaceae. This family has more than 200 genera and more than 4000 species. H. sabdariffa leaves are collected, and extracted by using different solvents, viz., petroleum ether, chloroform, ethyl acetate, ethanol and water. Extracts obtained are explored for their characteristic features. Among these extracts, AEHS was selected for further analysis by FTIR, HPLC and GC-MS techniques. Further, four phytoconstituents from H. sabdariffa, viz., beta-pinene, cyanidin, delphinidin, P-cymene are subjected for in silico antidepressant evaluation by using MAO-A, 2z5y protein. All the extracts obtained are brown to black in color and semisolid in nature. \% Yield was highest for AEHS (12.4\%). Phytochemical analysis showed the presence of various constituents like alkaloids, glycosides, tannins, flavonoids, anthocyanins, and phytosterols. AEHS FTIR spectrum showed the functional groups, viz., $1111 \mathrm{~cm}^{-1}$ and $1053 \mathrm{~cm}^{-1}$ corresponding to anthocyanins. HPLC analysis of AEHS also revealed the delphinidin and cyanidin related peaks with retention time of $22.81 \mathrm{~min}$ and $24.97 \mathrm{~min}$, respectively. GC-MS analysis of AEHS showed the presence of different phytoconstituents. Docking studies reported ligand protein interactions. Betapinene and p-cymene has not showed interaction with amino acids of $2 \mathrm{z} 5 \mathrm{y}$ protein. Therefore, these molecules are reported with weak dock score and low EModel energy. Whereas, cyanidin and delphinidin showed interaction with GLN (215), MET (445), and TYR (69) amino acids of MAO-A, 2z5y protein indicating their inhibitory action. Delphinidin with highest EModel energy, shows maximum in silico antidepressant effect by inhibiting MAO-A, 2z5y protein.
\end{abstract}

\section{Introduction}

For thousands of years, plants have been utilised to treat human ailments. It appears that Neanderthal man valued herbs as medical agents about 60,000 years ago; this conclusion is based on pollen grains from eight medicinal plants discovered in a cemetery in Iran (Solecki and Shanidar, 1975). The usage of medicinal herbs is not a relic of a bygone era. Approximately, $90 \%$ of the world's population still uses raw herbs and unprocessed extracts as their sole source of medication (Duke, 1985). According to a 1997 survey, 23\% of Canadians have taken herbal medications. Furthermore, plant components are found in up to $25 \%$ of modern pharmaceutical medications (Duke, 1983). Around 8,000 plant species are used in Indian medicine, including trees (33\%), herbs (32\%), shrubs (20\%), climbers (12\%), and epiphytes, grasses, lichens, ferns, and algae combined (3\%).

H. sabdariffa belonging to family Malvaceae, is one of the plants that has been used in traditional medicine for a long time, indicating that it contains bioactive components. This plant contains different constituents like, hydroxycitric acid, hibiscus acid, malic acid,

\section{Corresponding author: Dr. E. Bhavya}

Associate Professor, School of Pharmaceutical Sciences, Vels Institute of Science, Technology and Advanced Studies, Pallavaram, Chennai600117, Tamil Nadu, India

E-mail: mohd_masud@yahoo.com

Tel.: +91-9502039980

Copyright $\odot 2021$ Ukaaz Publications. All rights reserved.

Email: ukaaz@yahoo.com; Website: www.ukaazpublications.com tartaric acid (Yamada et al., 2007), cyanidin-3-sambubioside, cyanidin-3diglucoside, delphinidin-3 sambubioside (hibiscin), gossypin, hibiscitrin (hibiscetin-3 glucoside), kaempferol-3Orutinoside, myricetin, sabdaritrin, chlorgenic acid, pelargonidic acid, protocatechuic acid. Their pharmacological and toxicological properties, as well as their chemical composition, have all been extensively explored in recent years, indicating a growing interest in the characteristics of plants in human-dominated environments. This plant, which originated in tropical and subtropical regions, has spread throughout the globe, appearing in Asia (China, Thailand), Africa (Senegal, Egypt, Mali), Central America (Mexico, Jamaica, Panama), and even Europe (Da Costa Roca et al., 2014; Mohamed et al., 2012).

They are high in anthocyanins, flavonoids, vitamins, and microelements, according to studies conducted by Allarcon et al. (2012) and Peng et al. (2011). The genus contains approximately 300 species that thrive in all parts of the world and can withstand temperatures of over $20^{\circ} \mathrm{C}$. When ingested as medication or as part of a diet, the chemical content of the plant has therapeutic benefits. The plant has good effects on artery pressure, contributes to faster wound healing, is diuretic, antidiabetic, depressive, solves a variety of genital issues, plays a role in cholesterol stability, and is anticancerogenic when consumed as tea (Frank et al., 2012; Lin et al., 2012). Delphinidin-3-sambubioside and cyanidin-3sambubioside, anthocyanins extracted from the calyces of $H$. sabdariffa, exhibit substantial antioxidant and chemoprotective 
activities against hepatotoxicity caused bytertiary-butyl hydroperoxide (Wang et al., 2000). Flavonoids and anthocyanins have been linked to this extract's cardioprotective properties (Jonadet et al., 1990). By considering all these beneficial values present study is designed to extract, screen phytochemical analysis and in silico antidepressant activity of $H$. sabdariffa.

\section{Materials and Methods}

\subsection{Materials}

H. sabdariffa leaves were collected from in and around of Hyderabad in the month of Jan 2020. Plant material was subjected to authentication at Botanical Survey of India, Deccan region, Hyderabad. It was stored in Pharmacognosy Department with a Specimen No. MESCO_PCOG_2020_015. Chloroform, ethyl acetate, ethanol, petroleum ether are procured from SD Fine Chemicals Limited. All chemicals used in the study are of LR grade.

\subsection{Methods}

\subsubsection{Extraction of $\boldsymbol{H}$. sabdariffa leaves}

As mentioned above, collection and authentication of $H$. sabdariffa leaves was carried out. These leaves are checked for any impurities, kept for drying, grinded to coarse powder and finally subjected to successive solvent extraction by using Soxhlet apparatus. Soxhlet extraction was done by using following procedure: Defatting by of plant material was done by using petroleum ether $\left(40-60^{\circ} \mathrm{C}\right)(\mathrm{PEHS})$, then extraction was carried out by using different chemicals as chloroform $\left(60^{\circ} \mathrm{C}\right)(\mathrm{CEHS})$, ethyl acetate $\left(50-60^{\circ} \mathrm{C}\right)(\mathrm{EAEHS})$, ethanol $\left(40-60^{\circ} \mathrm{C}\right)\left(\right.$ EEHS), and aqueous $\left(60-70^{\circ} \mathrm{C}\right)(\mathrm{AEHS})$. Obtained extracts were left to air dry and semisolid form was obtained after few days. \% Yield was calculated for all the obtained extracts by using following formula:

$$
\% \text { Yield }=\left(\frac{\text { Weight } \text { of extract obtained in grams }}{\text { Total weight of raw material }}\right) \times 100
$$

\subsubsection{Phytochemical analysis of $\boldsymbol{H}$. sabdariffa leaves}

Preliminary phytochemical assessment was carried out to identify the presence of alkaloids, cardiac glycosides, tannins, phytosterols, proteins, amino acids and flavonoids by using standard procedures as described by Khandelwal (2007) (Shaji et al., 2019). The fourier transform infrared spectrophotometer (FTIR) is one of the most powerful techniques for identifying functional groups in substances. For FTIR analysis, dried aqueous extract was utilised. To make a translucent sample disc, $10 \mathrm{mg}$ of dried extract powder was encapsulated in $100 \mathrm{mg}$ of $\mathrm{KBr}$ pellet. Each plant specimen's powdered sample was placed into an FTIR spectroscope (Shimadzu, IR Affinity1, Japan), which has a scan range of 400 to $4000 \mathrm{~cm}^{-1}$ and a resolution of $4 \mathrm{~cm}^{-1}$. Further phytochemical evaluation of $H$. sabdariffa was performed by HPLC (Shimadzu Japan) analysis, by using $\mathrm{C} 18$ column. Instrument was operated at room temperature with $1 \mathrm{ml} / \mathrm{min}$ flow rate. Mobile phase consists of 2 solvents, viz., $0.1 \%$ trifluoroacetic acid in water (Sol-A) and $0.1 \%$ trifluoroacetic acid in acetonitrile (Sol-B). $100 \mathrm{mg}$ of extract was dissolved for 24 $\mathrm{h}$ with $5 \mathrm{ml}$ of methanol $\left(5^{\circ} \mathrm{C}\right)$. This solution of extract was centrifuged at $2500 \mathrm{rpm}$ for $15 \mathrm{~min}$, followed by collection of supernatants. This was filtered by using $0.45 \mu \mathrm{m}$ millipore membrane. This collected further diluted with double distilled water.
About $100 \mu$ l of filtrate was injected and analysis was conducted at $521 \mathrm{~nm}$. Elution program for analysis is as: for first $5 \mathrm{~min} 5-15 \%$ of Sol-B, then for next $10 \mathrm{~min}, 15-25 \%$ Sol-B was allowed, followed by $25-100 \%$ Sol-B for next $15 \mathrm{~min}$, and finally $100 \%$ of Sol-B for 30-40 min chlorogenic acid was used as an internal standard (Imad Uddin et al., 2020).

To carry out GC-MS analysis for $5 \mathrm{~h}, 10 \mathrm{~g}$ of AEHS was dissolved in 95\% ethanol. To eliminate the sediments and traces of water in the filtrate, the extract was filtered using Whatmann filter paper No.41 with $2 \mathrm{gm}$ sodium sulphate. The filter paper and sodium sulphate were wetted with $95 \%$ ethanol before filtering. Both polar and nonpolar phytocomponents of the plant material were present in the extract. This was subjected to GC-MS analysis by using "Trace DSQ GC-MS" analyzer. This equipment contains fused silica capillary column of length $30 \mathrm{~m}$, thickness $0.25 \mu \mathrm{m}$ and diameter $0.25 \mathrm{~mm}$. With a constant flow rate of $1 \mathrm{ml} / \mathrm{min}$ helium gas was used as carrier. Injection volume was $2 \mu 1$. Temperature of injector and ion-source was maintained at $250^{\circ} \mathrm{C}$ and $280^{\circ} \mathrm{C}$, respectively. In mass spectrometer, scan interval was about $0.5 \mathrm{sec}$ and fragments from $\mathrm{m} / \mathrm{z} 50$ to $500 \mathrm{Da}$ was programmed. Temperature of inlet and source was set to be $280^{\circ} \mathrm{C}$ and $250^{\circ} \mathrm{C}$, respectively. By comparing the average peak area of each component to the total areas, the relative percentage quantity of each component was computed. The GC-MS was performed by Central Instrumentation Research Laboratory, University College of Technology, Osmania University, Hyderabad.

\subsubsection{In silico analysis of $\boldsymbol{H}$. sabdariffa leaves aqueous extract}

The computational structure of the MAO-A was acquired from the Protein Databank website with PDB Id: $2 \mathrm{z} 5 \mathrm{y}$ in order to explore in silico antidepressant effects of AEHS. The structure was improved by removing unattached water molecules that were more than $1 \AA$. The energy of the entire structure was minimised by utilising the OPLS-2005 force field and the protein preparation wizard tool of the Schrodinger suite. Hydrogen atoms are added to satisfy the valences. Thereafter, amino acids are added to stabilize side chains. Using the Glide Xp docking methodology, structurally optimised protein was used to evaluate protein-ligand interactions of the dataset ligands. To begin, a 3D grid was created around the protein's binding site, into which all of the dataset ligands were docked. Glide score, which is a mix of hydrophilic, hydrophobic, metal binding groups, Vander Waals energy, frozen rotatable bonds, and polar interactions with receptor, was used to calculate binding interactions and efficiency (Abubucker, 2021).

To carry out post docking calculations, binding energies of the docked complexes were calculated using the Prime MM/GBSA (molecular mechanics based generalised born/surface area) module of the Schrodinger suite. This energy is the combination of OPLS molecular mechanics energies (EMM), an SGB solvation model for polar solvation (GSGB), and a non-polar solvation term (GNP) containing non-polar solvent accessible surface area and Vander Waals interactions. The findings of docking were rescored using an energy function that included a well-defined description of binding contributions. The total free energy of binding is then expressed as per below mentioned equation:

$\Delta \mathrm{G}_{\text {bind }}=\mathrm{G}_{\text {complex }}-\left(\mathrm{G}_{\text {protein }}+\mathrm{G}_{\text {ligand }}\right)$ where $\Delta \mathrm{G}_{\text {bind }}$ is binding energy of ligand. 


\section{Results}

3.1 Extraction, characteristic features and phytochemical analysis of $\boldsymbol{H}$. sabdariffa leaves

Successive solvent extraction process was used to extract $H$. sabdariffa leaves. Different solvents, viz., petroleum ether, chloroform, ethylacetate, ethanol and water are used for extraction process. EAEHS was brown in color, whereas PEHS was brownish black and all other extracts, viz., CEHS, EEHS, and AEHS are black in color. All these extracts are semi solid in nature. \% Yield was found to $12.4 \%$ for AEHS (highest) (Table 1). In H. sabdariffa leaves, screening was done with different chemical extracts and according to the standard tests. Presence of alkaloids was detected by using
Mayer's and Wagner's test. Alkaloids are found to present in all extracts. Molisch and benedict's test was carried out to check the presence of carbohydrates and was reported positive with all extracts. Both legal's and killer killani test showed positive results for the presence of cardiac glycosides in CEHS, EAEHS, and AEHS. Iodine and gelatin tests are positive for presence of tannins in CEHS and AEHS. Similarly, Salkowski's test and Libermann Bouchard test showed positive results for the presence of phytosterols in CEHS, EEHS, and AEHS. Proteins and amino acids showed presence in CEHS and EAEHS with positive results for both Ninhydrin and Millon's test. Whereas, alkaline reagent and lead acetate tests showed positive results for the presence of flavonoids in EAEHS, EEHS, and AEHS, EEHS and AEHS are positive only for anthocyanins (Table 2).

Table 1: Characteristics of different extracts of $\boldsymbol{H}$. sabdariffa leaves

\begin{tabular}{|c|c|c|c|c|c|}
\hline Extract & Color of the extract & Consistency of the extract & Wt. of the extract (gm) & Wt. of sample (gm) & $\%$ Yield \\
\hline PEHS & Brownish black & Semi-solid & 100 & 2.5 & 2.5 \\
\hline CEHS & Black & Semi-solid & 100 & 3.5 & 3.5 \\
\hline EAEHS & Brown & Semi-solid & 100 & 3.9 & 3.9 \\
\hline EEHS & Black & Semi-solid & 100 & 7.8 & 7.8 \\
\hline AEHS & Black & Semi-solid & 100 & 12.4 & 12.4 \\
\hline
\end{tabular}

Table 2: Phytochemical screening of different extracts of $\boldsymbol{H}$. sabdariffa leaves

\begin{tabular}{|c|c|c|c|c|c|c|}
\hline S.No. & Phytochemical constituents & PEHS & CEHS & EAEHS & EEHS & AEHS \\
\hline 1 & $\begin{array}{l}\text { Alkaloids } \\
\text { 1. Mayers test } \\
\text { 2. Wagners test }\end{array}$ & ++ & +- & +- & +- & ++ \\
\hline 2 & $\begin{array}{l}\text { Carbohydrates } \\
\text { 1. Molish test } \\
\text { 2. Benidicts test }\end{array}$ & ++ & ++ & +- & ++ & +- \\
\hline 3 & $\begin{array}{l}\text { Cardiac glycosides } \\
\text { 1. Legals test } \\
\text { 2. Killerkallani test }\end{array}$ & +- & ++ & ++ & +- & ++ \\
\hline 4 & $\begin{array}{l}\text { Tannins } \\
\text { 1. Iodine test } \\
\text { 2. Gelatin test }\end{array}$ & +- & +- & ++ & +- & ++ \\
\hline 5 & $\begin{array}{l}\text { Phytosterol } \\
\text { 1. Salkowiskis test } \\
\text { 2. Libermann buchard test }\end{array}$ & +- & ++ & +- & ++ & ++ \\
\hline 6 & $\begin{array}{l}\text { Proteins and aminoacids } \\
\text { 1. Ninhydrin test } \\
\text { 2. Millons test }\end{array}$ & -- & ++ & ++ & +- & +- \\
\hline 7 & $\begin{array}{l}\text { Flavonoids } \\
\text { 1. Alkaline reagent test } \\
\text { 2. Lead acetate test }\end{array}$ & +- & +- & ++ & ++ & ++ \\
\hline 8 & Anthocyanins & - & - & - & + & + \\
\hline
\end{tabular}


Based on these characteristic and phytochemical screening results, AEHS was selected for further studies. FTIR analysis of AEHS was conducted to evaluate the presence of various functional groups. Peak at $3441 \mathrm{~cm}^{-1}$ corresponds to asymmetric stretching vibration of primary amine, i.e., $-\mathrm{NH}_{2}$ and peak at $3387 \mathrm{~cm}^{-1}$ is responsible for symmetric stretching vibration of the same $-\mathrm{NH}_{2}$ group. Two peaks, viz., $3404 \mathrm{~cm}^{-1}$ and $3421 \mathrm{~cm}^{-1}$ corresponds to $-\mathrm{OH}$ stretching or $-\mathrm{NH}$ stretching vibrations. Peaks at $2362 \mathrm{~cm}^{-1}$ and $2347 \mathrm{~cm}^{-1}$ are representing $\mathrm{O}=\mathrm{C}=\mathrm{O}$ stretching vibrations. $1629 \mathrm{~cm}^{-1}$ peak corresponds to vibration stretching of $\mathrm{C}=\mathrm{O}$ group, $1394 \mathrm{~cm}^{-1}$ and $1383 \mathrm{~cm}^{-1}$ corresponds to $-\mathrm{OH}$ bending vibrations. Whereas, peaks at $1111 \mathrm{~cm}^{-1}$ and $1053 \mathrm{~cm}^{-1}$ corresponds to anthocyanins (Figure 1). HPLC analysis of AEHS showed the presence of two peaks, viz., $22.81 \mathrm{~min}$ and $24.97 \mathrm{~min}$ which corresponds to delphinidin and cyanidin, respectively. $27.39 \mathrm{~min}$ peak represents chlorogenic acid (Figure 2). GCMS analysis revealed the presence of different constituents. $1^{\text {st }}$ peak with retention time (RT) of 0.021 min indicates 2-heptanamine, 5-methyl with $\%$ area of 0.51 . Next peaks with RT of $1.121 \mathrm{~min}$ and $2.029 \mathrm{~min}$ indicate 1,3-propanediol, 2-methyl-2nitro-, dinitrate and 1,2,3-propanetriol, 1,3-dinitrate, respectively. $\mathrm{P}$-cymene a triterpenoid was reported with RT of $5.124 \mathrm{~min}$. It has $1.46 \%$ area and molecular formula as $\mathrm{C}_{10} \mathrm{H}_{14}$. Similarly, $\mathrm{RT}$ at 8.059 min indicates beta-pinene in our study with 1.98 of $\%$ area and $93.57 \mathrm{~m} / \mathrm{z}$ value. Peak at RT value of $9.331 \mathrm{~min}$ indicates delphinidin, which is having a \%area of 1.73 and 300 as the $\mathrm{m} / \mathrm{z}$ value. Cyanidine is an another important phytoconstituent reported in GC-MS analysis with RT at 17.12 and $280.05 \mathrm{as} \mathrm{m} / \mathrm{z}$ value. 9-Octadecenoic acid or oleic acid is reported at 20.308 with \%area of peak as 7.15. Other constituents which are reported are 2-acetylbenzoic acid, hexadecanoic acid, methyl ester and methyl E-11-tetradecenoate at RT values of 14.43, 18.215, and 44.145, respectively (Figure 3 and Table 3).

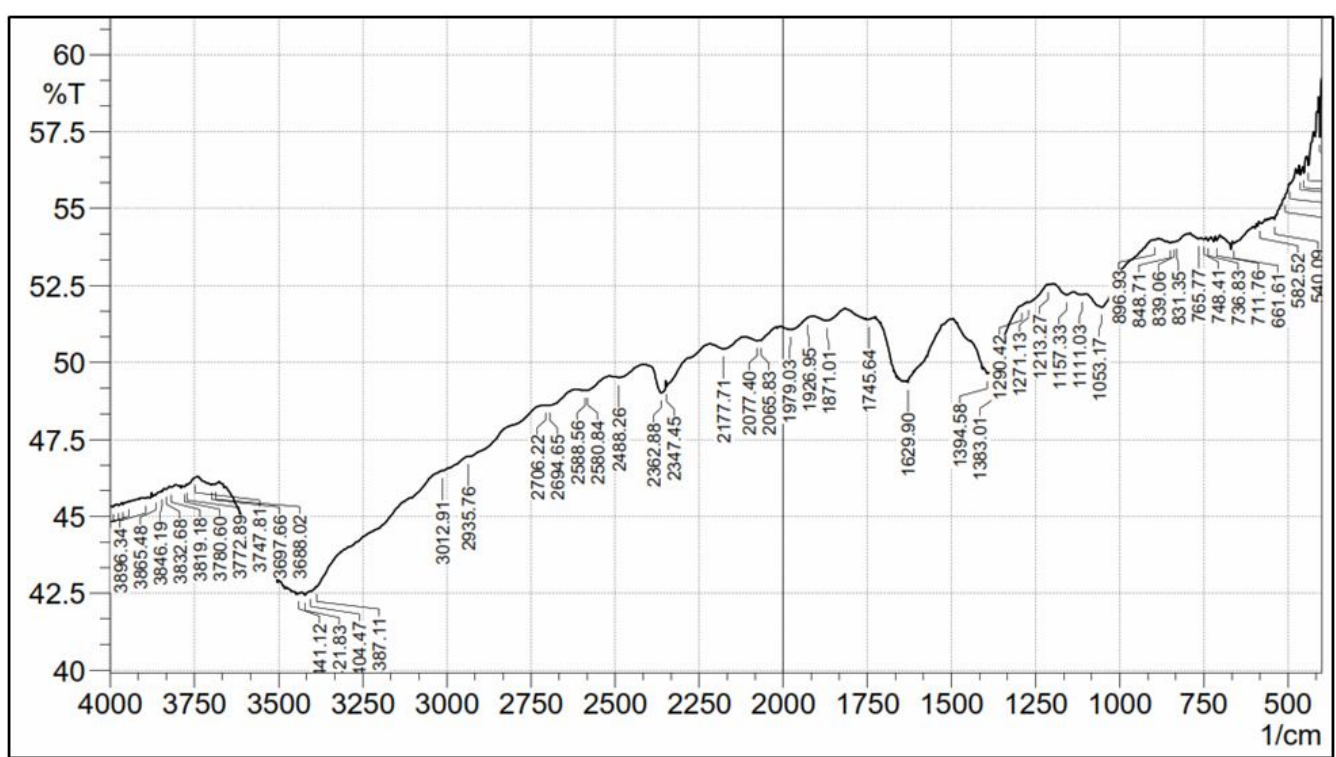

Figure 1: FTIR analysis of AEHS.

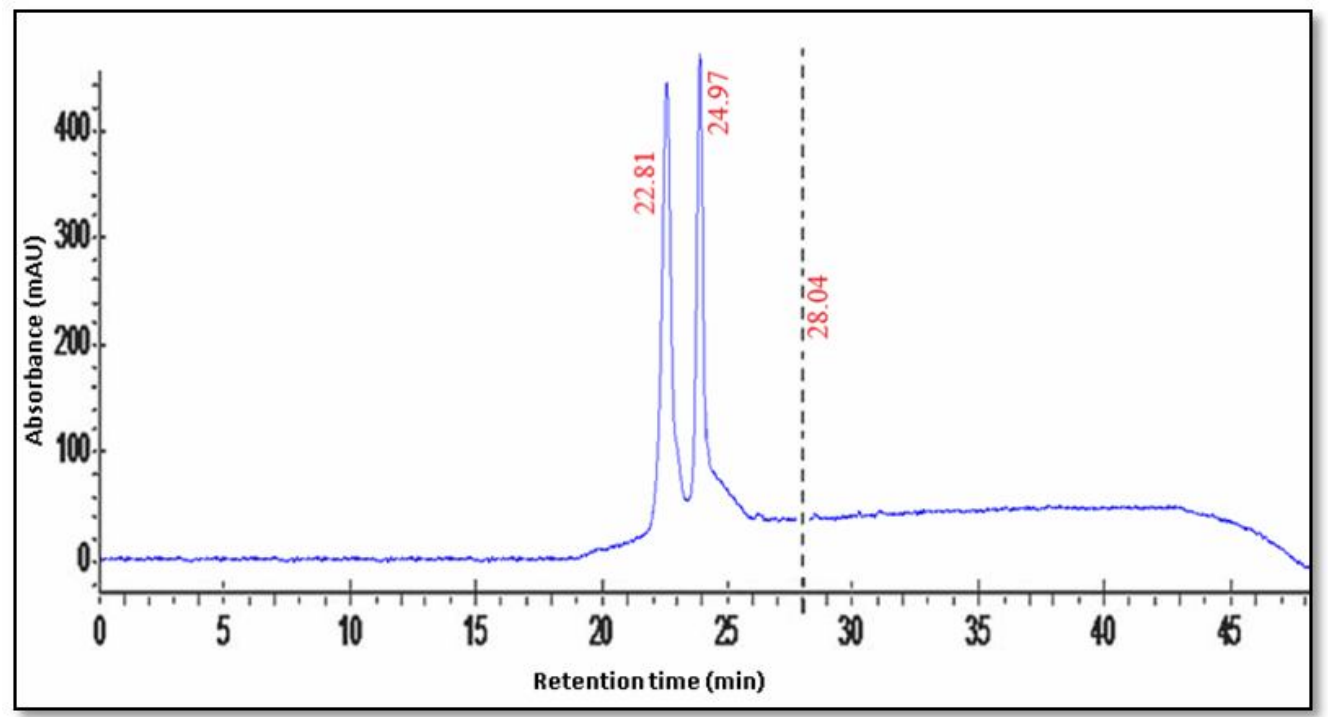

Figure 2: HPLC chromatogram of AEHS. 


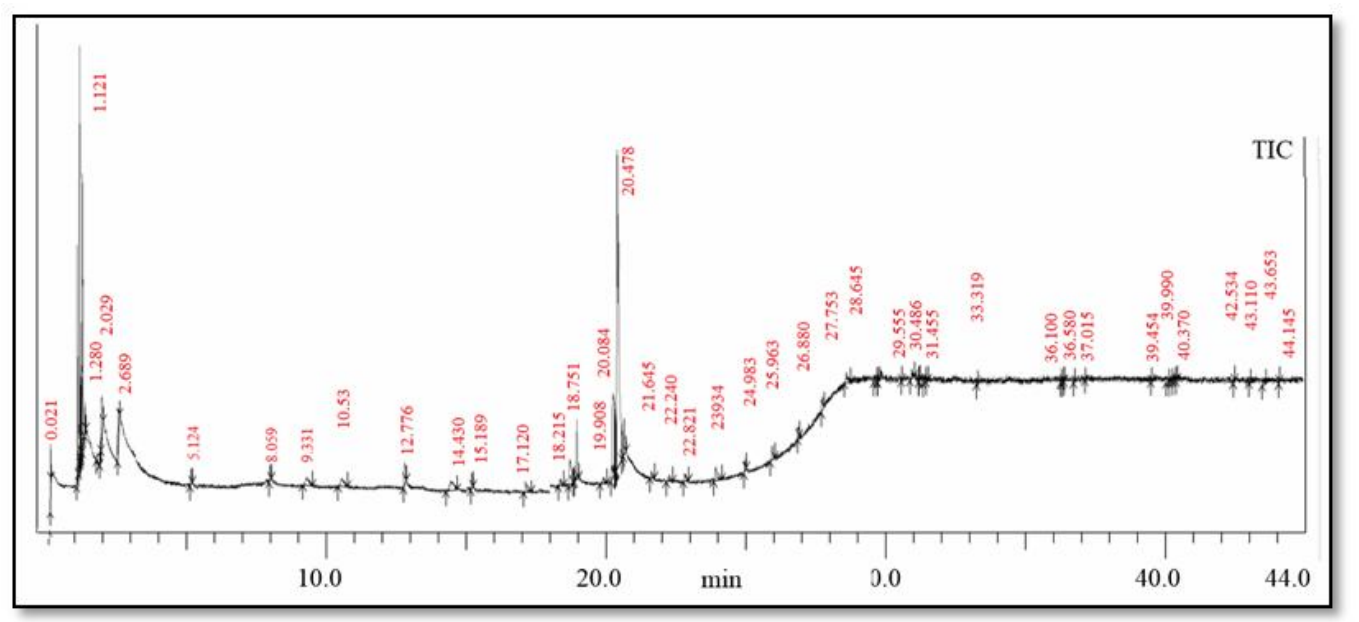

Figure 3: GC-MS analysis of AEHS.

Table 3: GC-MS analysis of AEHS

\begin{tabular}{|c|l|l|c|c|c|c|}
\hline Peak & R. time & Name & $\begin{array}{c}\text { Molecular } \\
\text { formula }\end{array}$ & $\begin{array}{c}\text { Molecular } \\
\text { weight (g/mol) }\end{array}$ & $\begin{array}{c}\text { Area } \\
\text { \% }\end{array}$ & $\begin{array}{c}\text { Base m/z } \\
\text { value }\end{array}$ \\
\hline 1 & 0.021 & 2-heptanamine, 5-methyl- & $\mathrm{C}_{8} \mathrm{H}_{19} \mathrm{~N}$ & 129.24 & 0.51 & 44.05 \\
2 & 1.121 & 1,3-propanediol, 2-methyl-2-nitro-, dinitrate & $\mathrm{C}_{4} \mathrm{H}_{7} \mathrm{~N}_{3} \mathrm{O}_{8}$ & 225.1 & 8.26 & 45.75 \\
3 & 2.029 & $1,2,3$-propanetriol, 1,3-dinitrate & $\mathrm{C}_{3} \mathrm{H}_{6} \mathrm{~N}_{2} \mathrm{O}_{7}$ & 182.08 & 2.76 & 45.85 \\
4 & 5.124 & p-cymene & $\mathrm{C}_{10} \mathrm{H}_{14}$ & 134.2 & 1.46 & 85.16 \\
5 & 8.059 & Beta-pinene & $\mathrm{C}_{10} \mathrm{H}_{16}$ & 136.23 & 1.98 & 93.57 \\
6 & 9.331 & Delphinidin & $\mathrm{C}_{15} \mathrm{H}_{11} \mathrm{O}_{7}$ & 303.2 & 1.73 & 300 \\
7 & 10.533 & Cyclohexasiloxane, dodecamethyl- & $\mathrm{C}_{12} \mathrm{H}_{36} \mathrm{O}_{6} \mathrm{Si}_{6}$ & 444.9 & 1.01 & 73.05 \\
8 & 14.43 & 2-Acetylbenzoic acid & $\mathrm{C}_{9} \mathrm{H}_{8} \mathrm{O}$ & 164.16 & 1.70 & 149.0 \\
9 & 17.12 & Cyanidine & $\mathrm{C}_{15} \mathrm{H}_{11} \mathrm{O}_{6}+$ & 287.2 & 0.59 & 280.05 \\
10 & 18.215 & Hexadecanoic acid, methyl ester & $\mathrm{C}_{17} \mathrm{H}_{34} \mathrm{O}_{2}$ & 270.45 & 0.33 & 74.00 \\
11 & 20.308 & 9-Octadecenoic acid & $\mathrm{C}_{18} \mathrm{H}_{34} \mathrm{O}_{2}$ & 282.47 & 7.15 & 55.05 \\
12 & 44.145 & Methyl E-11-tetradecenoate & $\mathrm{C}_{15} \mathrm{H}_{30} \mathrm{O}_{2}$ & 242.40 & 0.13 & 252.85 \\
\hline
\end{tabular}

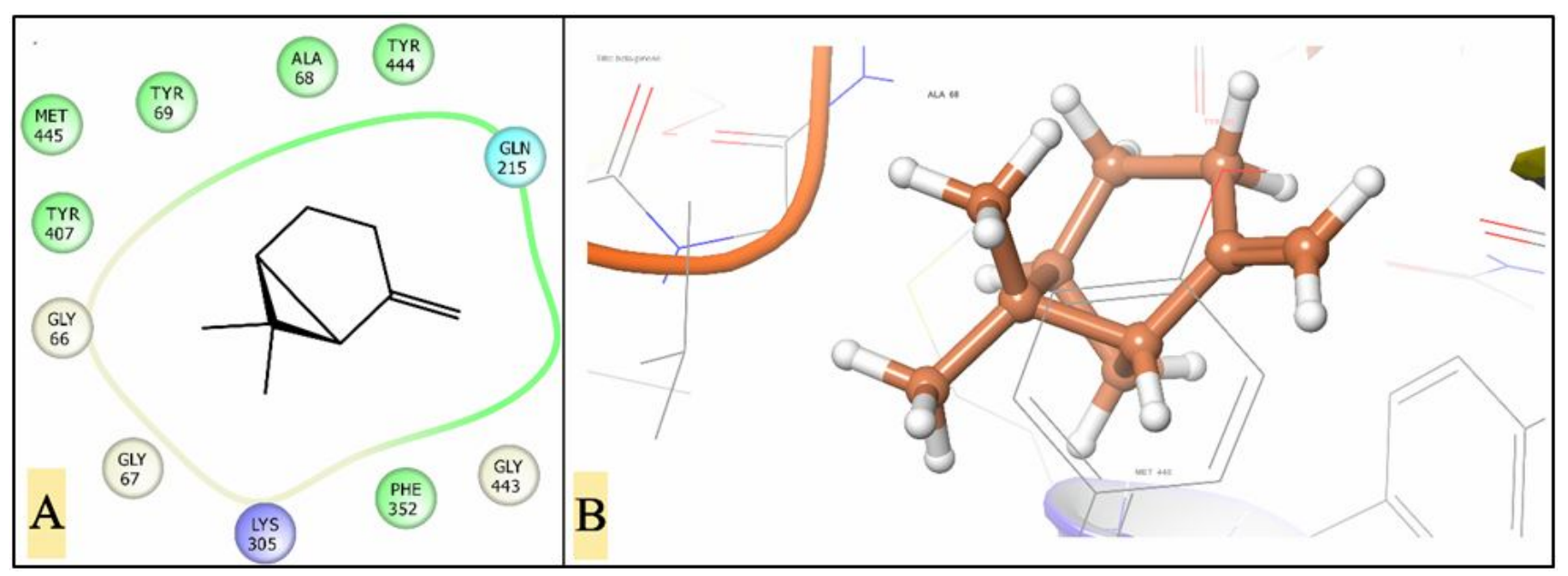

Figure 4: A-beta-pinenedoes not show binding interactions with amino acids of MAO-A, 2z5y protein. B-2D representation of beta-pinene, where it is not showing binding interactions with amino acids of MAO-A, 2 z5y protein. 
After successful characterization of AEHS by FTIR, HPLC and GCMS analytical techniques, four constituents, viz., beta-pinene, cyanidin, delphinidin, and p-cymene are screened for in silico antidepressant efficacy by using MAO-A, 2z5y as a target protein. Glide XP module generates many protein ligand complexes for each protein ligand interaction but the complex having highest EModel energy is only represented in results. Table 4 explains about glide dock score, number of $\mathrm{H}$-bonds, interacting amino acids, $\mathrm{H}$-bond distance in $\AA$, glide energy and EModel energy. Beta-pinene does not interact with any amino acid (Figure $4 \mathrm{~A}$ and $\mathrm{B}$ ), with very low dock score of -4.794 and a very low EModel energy of $-11.61 \mathrm{kcal} / \mathrm{mol}$.
Cyanidine have 3 hydrogen bonds and showed interaction with 3 amino acids, viz., GLN (215), MET (445), and TYR (69). Both dock score and EModel energy was found to be more than beta-pinene as -6.896 and $-42.299 \mathrm{kcal} / \mathrm{mol}$, respectively (Figure 5A and B). On the lead among four constituents, delphinidin have 5 hydrogen bonds and interacts with 4 different amino acids, i.e., GLY (443), GLN (215), MET (445), and TYR (69). It is also reported with highest dock score and EModel energy as -7.055 and $-49.299 \mathrm{kcal} / \mathrm{mol}$, respectively (Figure 6A and B). P-cymene with no hydrogen bond does not interact with any amino acids and have -5.43 as dock score and $-26.454 \mathrm{kcal} / \mathrm{mol}$ as EModel energy (Figure $7 \mathrm{~A}$ and $\mathrm{B}$ ).

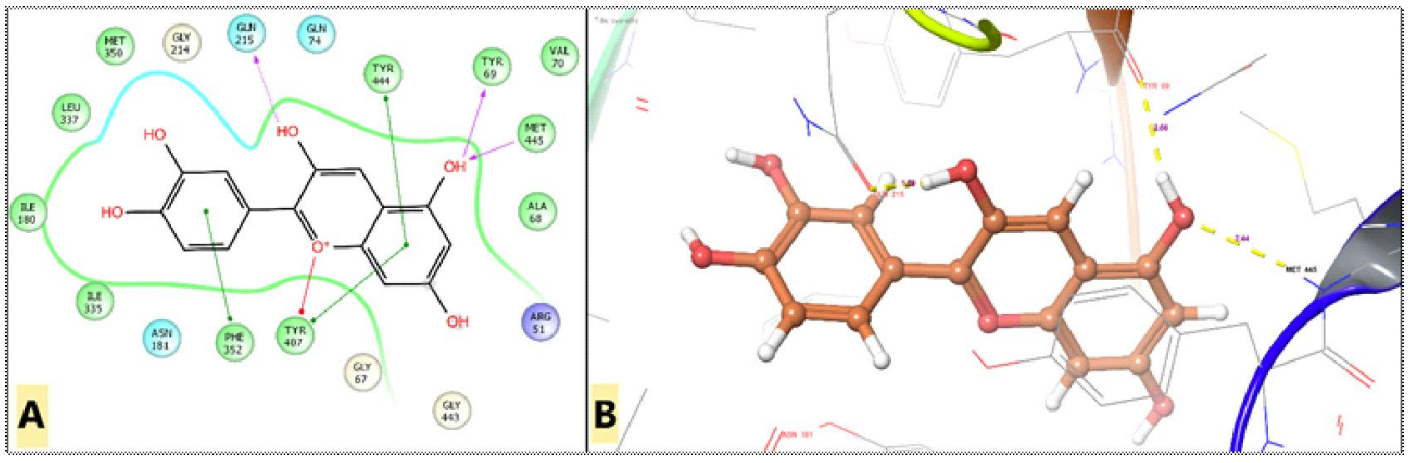

Figure 5: A-cyanidine shows binding interactions with GLN (215), MET (445), and TYR (69)amino acids of MAO-A, 2z5y protein. B-2D representation of cyanidine, where it is showing binding interactions with amino acids of MAO-A, $2 z 5 y$ protein.

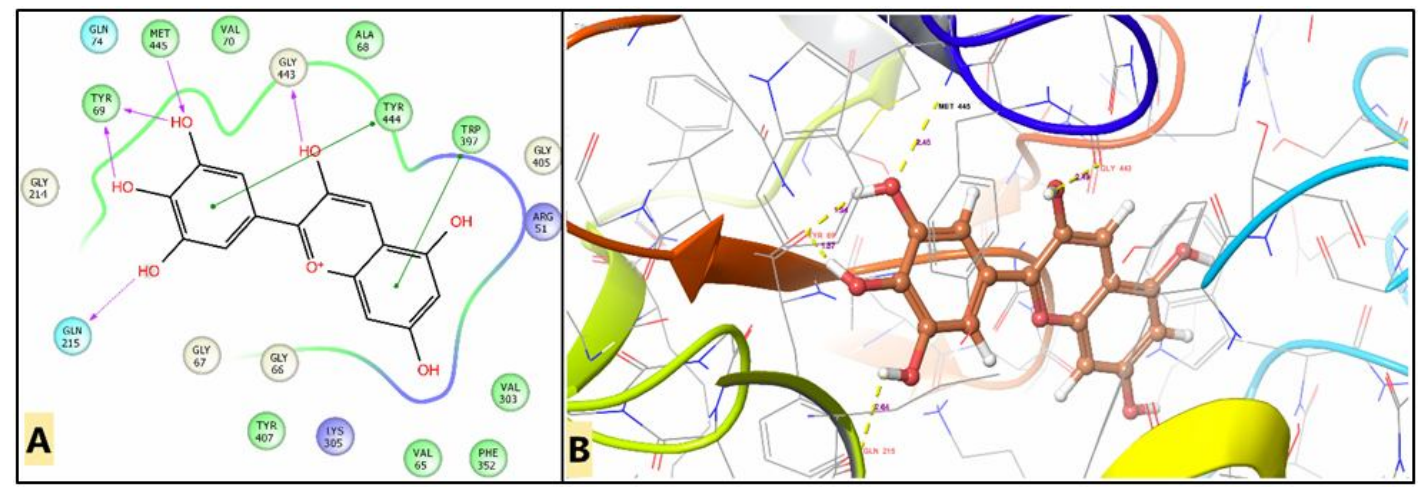

Figure 6: A-delphinidinshows binding interactions with GLY (443), GLN (215), MET (445), and TYR (69) amino acids of MAO-A, 2z5y protein. B-2D representation of delphinidin, where it is showing binding interactions with amino acids of MAO-A, $2 \mathrm{z5y}$ protein.

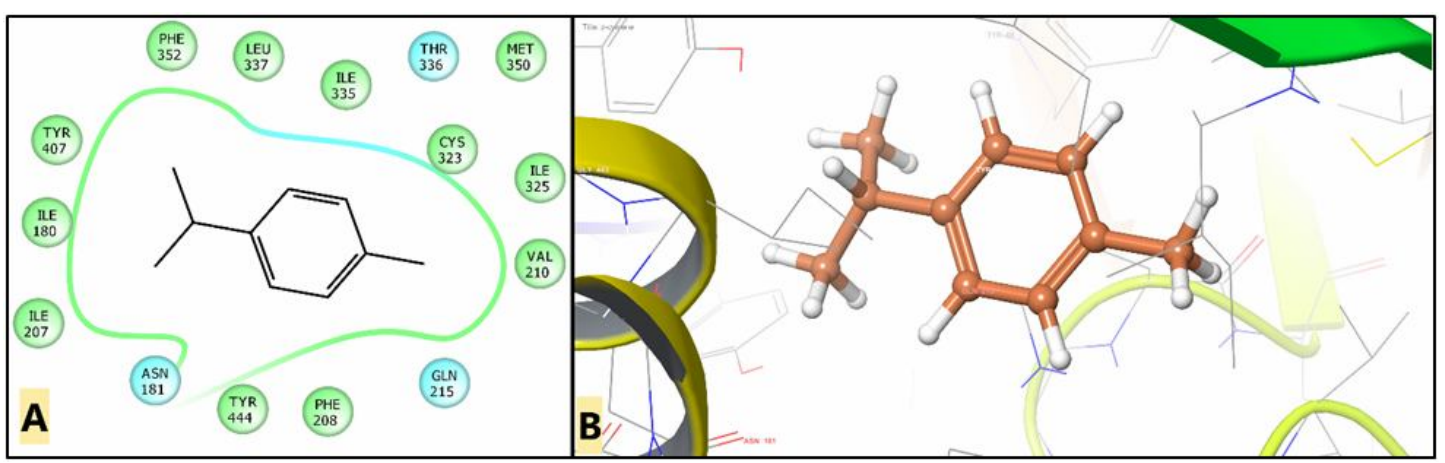

Figure 7: A-P-cymene does not show binding interactions with amino acids of MAO-A, 2z5y protein. B-2D representation of p-cymene, where it is not showing binding interactions with amino acids of MAO-A, 2z5y protein. 
Table 4 : Docking results and protein-ligand binding interactions of different phytoconstituents of $H$. sabdariffa against MAOA, 2z5y protein

\begin{tabular}{|c|c|c|c|c|c|c|}
\hline Compound & Dock score & No. of H-bonds & $\begin{array}{l}\text { Interacting } \\
\text { amino acids }\end{array}$ & $\begin{array}{c}\text { H-bond } \\
\text { distance }(\AA)\end{array}$ & Glide energy & EModel energy \\
\hline Beta-pinene & -4.794 & 0 & - & - & -17.421 & -11.611 \\
\hline \multirow[t]{3}{*}{ Cyanidin } & -6.896 & 3 & GLN 215 & 1.59 & & \\
\hline & & & MET 445 & 2.44 & -36.943 & -42.299 \\
\hline & & & TYR 69 & 2.06 & & \\
\hline \multirow[t]{4}{*}{ Delphinidin } & -7.055 & 5 & GLY 443 & 2.49 & & \\
\hline & & & GLN 215 & 2.64 & -38.476 & -49.492 \\
\hline & & & MET 445 & 2.45 & & \\
\hline & & & TYR 69 & $1.94,1.87$ & & \\
\hline P-cymene & -5.436 & 0 & - & - & -21.878 & -26.454 \\
\hline
\end{tabular}

\section{Discussion}

The Malvaceae family includes $H$. sabdariffa (Roselle). In this plant $8-15 \mathrm{~cm}$ long, deeply three-to five-lobed leaves are placed alternately on the stalks. In English-speaking regions, rozelle, sorrel, red sorrel, and roselle are some of the common names for $H$. sabdariffa. Our study reported the good yield of ethanol and water extract as $7.8 \%$ and $12.4 \%$, respectively. Different phytoconstituents are reported in various extracts of these leaves. Our study reported the presence of alkaloids which are in accordance with the results of Nkumah et al. (2015). Presence of phytosterols and glycosides reported in our study is also in accordance with the results of Aguirre-Garcia et al. (2019), where they reported the presence of many phytoconstituents like pigments (major pigment as cyanidine-3-glycoside), phytosterols, carbohydrates and glycosides in complete plant extract. Flavonoids a therapeutic potential phytoconstituent reported in our study is also reported in calyces by Alara et al. (2020).

FTIR spectroscopic analysis showed the presence of various functional groups in AEHS. In our study, two peaks $3441 \mathrm{~cm}^{-1}$ and $3387 \mathrm{~cm}^{-1}$ representing $-\mathrm{NH}_{2}$ stretching was also reported by Fatoni et al. (2018). $-\mathrm{OH}$, stretching peaks of amide reported in our study are $3404 \mathrm{~cm}^{-1}$ and $3421 \mathrm{~cm}^{-1}$, similar peaks corresponding to $-\mathrm{OH}$ stretching like $3404 \mathrm{~cm}^{-1}$ and $3420 \mathrm{~cm}^{-1}$ are reported by Suresh et al. (2016). Similar $2362 \mathrm{~cm}^{-1}$ and $2347 \mathrm{~cm}^{-1}$ peaks representing $\mathrm{O}=\mathrm{C}=\mathrm{O}$ stretching are also reported by Alia et al. (1997). In the same way, $1111 \mathrm{~cm}^{-1}$ and $1053 \mathrm{~cm}^{-1}$ corresponding to anthocyanins is also reported by Paraiso et al. (2020).

After FTIR analysis, HPLC analysis of AEHS was conducted to evaluate the presence of various constituents. RT values of delphinidin and cyanidin reported in our study are in close accordance with the study conducted by Villalpando et al. (2013) as $27 \mathrm{~min}$ and $28.5 \mathrm{~min}$ fordelphinidin and cyanidin, respectively. gas chromatography is usually combined with mass spectroscopy to explore the presence of various constituents in plant extracts. Pcymene reported in our study is in accordance with the results of Pavlic et al. (2020) where p-cymene was reported with the RT of $5.283 \mathrm{~min}$. Beta-pinene an important component of essential oil in many plants is also reported with a RT value of 8.059 , this was also reported in the essential oil extracted from leaves and calyces of
H. sabdariffa plant material collected from Iran by Amlashi et al. (2020). Delphinidin, is an important anthocyanidin pigment reported in GC-MS analysis, this was also reported Bochi et al. (2015) with a very near $\mathrm{m} / \mathrm{z}$ value of 303 . Another important anthocyanidin; reported in our study is cyanidine, our results are in accordance with the study conducted by Gouvea et al. (2012), where a very near $\mathrm{m} / \mathrm{z}$ value of 287 was reported for cyanidine. Successfully, characterized AEHS revealed the use of four different phytoconstituents for in silico studies by using MAO-A, $2 \mathrm{z} 5 \mathrm{y}$ protein. Among all four phytoconstituents screened, delphinidin showed maximum inhibition of MAO-A, 2z5y protein with highest dock score and EModel energy as -7.055 and $-49.299 \mathrm{kcal} / \mathrm{mol}$, respectively.

\section{Conclusion}

In conclusion, we report the importance of $H$. sabdariffa leaves as a rich source of various phytoconstituents. FTIR analysis of AEHS showed the presence of different functional groups and HPLC analysis reported the peaks of delphinidin and cyanidin. GC-MS analysis of AEHS showed the presence of more than 10 different phytoconstituents among which four were selected for evaluating in silico antidepressant effect. Delphinidin and cyanidin showed good docking score against MAO-A, 2z5y protein indicating their efficacy against depression. Authors are further exploring AEHS in vivo antidepressant activity. Further, bioactivity guided isolation can also be conducted to get highly effective compounds for the treatment of depression.

\section{Conflict of interest}

The authors declare no conflicts of interest relevant to this article.

\section{References}

Abubucker Peer Mohideen (2021). In silico identification of novel immunostimulating phytochemicals withacetylcholinesterase inhibition activity from Piper betle L. and Vitex negundo L. for the treatment of Alzheimer'sdisease (AD): Ann. Phytomed., 10(1):8695. http://dx.doi.org/10.21276/ap.2021.10.1.9

Aguirre-Garcia, F.; Yanez-Lopez, L.; Armella, M.A. and Verde, J.R. (2019). Studies from Hibiscus sabdariffa (Hibiscus) plant for blood cholesterol levels reduction. American Journal of Plant Sciences, 10(04):497. 
Alara, O.R.; Abdurahman, N.H.; Obanijesu, E.O.; Alara, J.A. and Abdul Mudalip, S.K. (2020). Extract rich in flavonoids from Hibiscus sabdariffa calyces: Optimizing microwave assisted extraction method and characterization through LC Q TOF MS analysis. J. Food Process Eng., 43(2):e13339.

Alarcon-Alonso, J.; Zamilpa, A.; Aguilar, F.A.; HerreraRuiz, M.; Tortoriello, J. and Jimenez-Ferrer, E. (2012). Pharmacological characterization of the diuretic effect of Hibiscus sabdariffa Linn (Malvaceae) extract. J. Ethnopharmacol., 139(3):751-756

Alia, J.M.; De Mera, Y.D.; Edwards, H.G.M.; Martin, P.G. and Andres, S.L. (1997) FT-Raman and infrared spectroscopic study of aragonite-strontianite (CaxSr1" xCO3) solid solution. Spectrochimica Acta Part A Molecular and Biomolecular Spectroscopy, 53(13):2347-2362.

Amlashi, H.A.; Madani, H.; Sonboli, A.; Khaghani, S. and Ramezani, M. (2020). Volatile composition of the leaves and calyces' essential oil of roselle (Hibiscus sabdariffa L.) from Iran. Journal of Essential OilBearing Plants, 23(4):743-755.

Bochi, V.C.; Godoy, H.T. and Giusti, M.M. (2015). Anthocyanin and other phenolic compounds in Ceylon gooseberry (Dovyalis hebecarpa) fruits. Food Chem., 176:234-243.

Da-Costa-Rocha, I.; Bonnlaender, B.; Sievers, H.; Pischel, I. and Heinrich, M. (2014) Hibiscus sabdariffa L.: A phytochemical and pharmacological review, Food Chem., 165:424-443

Duke, J.A. (1983). Medicinal plants of the Bible. Trade-Medic Books, Buffalo, NY, pp:233

Duke, J.A. (1985). Handbook of Medicinal Herbs. CRC Press Inc., Boca Raton, FL, pp:677.

Fatoni, A.; Hariani, P.L.; Hermansyah, H. and Lesbani, A. (2018). Synthesis and characterization of chitosan linked by methylene bridge and schiff base of 4, 4-Diaminodiphenyl ether-vanillin. Indonesian Journal of Chemistry, 18(1):92-101.

Frank, T.; Netzel, G.; Kammerer, D.R.; Carle, R.; Kler, A.; Kriesl, E.; Bitsch, I. Bitsch, R. and Netzel, M. (2012). Consumption of Hibiscus sabdariffa L. aqueous extract and its impact on systemic antioxidant potential in healthy subjects. J. Sci. Food Agr., 92(10):2207-2218.

Gouvea,A.C.M.S.; Araujo, M.C.P.D.; Schulz, D.F.; Pacheco, S.; Godoy, R.L.D.O. and Cabral, L.M.C. (2012). Anthocyanin's standards (cyanidin-3-O-glucoside and cyanidin-3-O-rutinoside) isolation from freeze-dried açaí (Euterpe oleraceae Mart.) by HPLC. Food Sci. Tech., 32(1):43-46.

Imad Uddin, M.D.; Venkata Raja Srikar,P.; Preethi, K.; Y.; Rachana, C. and Deepika, R. (2020). Synthesisand characterization of chitosan nanoparticles loaded with 6-gingerol isolated from Zingiber officinale Rosc. Ann. Phytomed., 9(2):164-171.

Jonadet, M.; Bastide, J. and Bastide, P. (1990). Activités in hibitricesenzy matiques in vitro etangio protectrice in vivo d'extraits de karkadé (Hibiscus sabdariffa L.). Journal De PharmacieDe Belgique, 45:120124.
Khandelwal, K.R. (2007). Practical Pharmacognosy: Techniques and Experiments. 2nd ed. Pune: Nirali Prakashan, pp:149-55.

Lin, H.H.; Chan, K.C.; Sheu, J.Y.; Hsuan, S.W.; Wang, C.J. and Cheng, J.H. (2012). Hibiscus sabdariffa leaf induces apoptosis of human prostate cancer cells in vitro and in vivo. Food Chem., 132(2):880-891.

Mohamed, B.B.; Sulaiman, A.A. and Dahab, A.A. (2012). Roselle (Hibiscus sabdariffa L.) in Sudan, cultivation and their uses. Bulletin of Environment, Pharmacology and Life Sciences, 1(6):48-54.

Nkumah, O.C.; Iroka, F.C. and Chukwuma, M.O. (2015). Phytochemical analysis and medicinal uses of Hibiscus sabdariffa. International journal of Herbal Medicine, 2(6):16-19.

Paraiso, C.M.; dos Santos, S.S.; Ogawa, C.Y.L.; Sato, F.; dos Santos, O.A. and Madrona, G.S. (2020).Hibiscus sabdariffa L. extract: Characterization (FTIR-ATR), storage stability and food application. Emir. J. Food Agr., 32:55-61.

Pavlic, B.; Teslić, N.; Kojić, P. and Pezo, L. (2020). Prediction of the GC-MS retention time for terpenoids detected in sage (Salvia officinalis L.) essential oil using QSRR approach. J. Serb. Chem. Soc., 85(1):9-23.

Peng, C.H.; Chyau, C.C.; Chan, K.C.; Chan, T.H.; Wang, C.J. and Huang, C.N. (2011) Hibiscus sabdariffa polyphenolic extract inhibits hyperglycaemia, hyperlipidaemia, and glycation-oxidative stress while improving insulin resistance. J. Agr. Food Chem., 59(18):9901-9909.

Shaji, E.M.; Smitha, K.R.; Thekkekara, D.B.; Kuzhivelil, B.T. and Achuthan, C.R. (2019). Preliminary assessment on phytochemical composition, cytotoxic and antitumor efficacy of Simarouba glauca DC. leaf methanolic extract. Ann. Phytomed., 8(2):121-126.

Solecki, R.S. and Shanidar, I.V. (1975). Neanderthal flower burial in northern Iraq. Science, 190(4217):880-881.

Suresh, S.; Karthikeyan, S. and Jayamoorthy, K. (2016). FTIR and multivariate analysis to study the effect of bulk and nano copper oxide on peanut plant leaves. Journal of Science: Advanced Materials and Devices, 1(3):343-350.

Wang, C.J.; Wang, J.M. and Lin, W.L. (2000). Protective effect of Hibiscus anthocyanins against tertbutylhydroperoxide induced hepatic toxicity in rats. Food Chem. Toxicol., 38:411-416.

Villalpando-Arteaga, E.V.; Mendieta-Condado, E.; Esquivel-Solís, H.; CanalesAguirre, A.A.; Gálvez-Gastélum, F.J.; Mateos-Díaz, J.C.; Rodríguez-González, J.A. and Márquez-Aguirre, A. L. (2013). Hibiscus sabdariffa L. aqueous extract attenuates hepatic steatosis through down-regulation of PPAR- $\gamma$ and SREBP-1c in diet-induced obese mice. Food Funct, 4(4):618-626.

Yamada, T.;Hida, H. and Yamada, Y. (2007). Chemistry, physiological properties, and microbialproduction of hydroxycitric acid. Appl. Microbiol. Biotechnol., 75:977-982.

Mohd Mohiuddin Shareef and E. Bhavya (2021). Extraction, phytochemical analysis and in silico antidepressant 